\title{
Perigo do auto-tratamento da apnéia obstrutiva do sono com CPAP
}

A síndrome da apnéia obstrutiva do sono (SAOS) é doença de alta prevalência, sendo freqüentemente tratada com um equipamento que fornece pressão positiva contínua na via aérea (CPAP) ou um aparelho reposicionador mandibular intraoral (ARMIO). Já está provado que o tratamento da SAOS com o CPAP pode definitivamente modificar a vida do paciente, melhorando sua qualidade e reduzindo seus riscos cárdio-cérebro-vasculares.

Um paciente com SAOS apresenta várias comorbidades, associadas ou não ao quadro de apnéia, muitas vezes dependentes dele, mas principalmente podem ser predisponentes e agravantes da condição de saúde. Assim, para o adequado tratamento, o paciente precisa se conscientizar de que, dentre outras atitudes, deve perder peso; evitar bebida alcoólica em horário próximo ao de dormir, devido ao relaxamento muscular que o álcool provoca, aumentando os eventos apnêicos; deve evitar alimentação copiosa próximo ao horário de dormir; integrar-se em um programa de atividade física; e usar, quando for indicado, o CPAP ou ARMIO.

O modelo ético, responsável e correto de se tratar um paciente com SAOS é relativamente simples, embora nem sempre haja disponibilidade para isso em todos os lugares do Brasil, sendo também um problema de vários países do mundo. O paciente ao procurar um médico e ser diagnosticado como tendo SAOS, será encaminhado para realização de nova polissonografia, quando então usará um CPAP controlado pelo técnico do laboratório de sono. Neste procedimento será determinado qual pressão elimina as apnéias, o ronco e os microdespertares do paciente, em todas as fases do sono e nos vários decúbitos, principalmente o dorsal.

Uma vez realizado este procedimento, o médico receberá, em seu consultório ou ambulatório, um laudo de exame dizendo qual a pressão de CPAP foi necessária para tratar aquele paciente naquela noite de teste. Independentemente do quão exata esta pressão possa ser, o médico a utilizará como base de tratamento e emitirá uma receita com parâmetros importantes a serem configurados no equipamento de CPAP que o paciente irá adquirir para seu tratamento.

Uma vez em posse da receita o paciente deverá dirigir-se a uma empresa que forneça o equipamento. Estas empresas passaram a assumir um trabalho que anteriormente era executado pelos médicos em seus consultórios, ou seja, configurar o equipamento conforme a receita médica. Esta "gentileza" pode ter ajudado, mas abriu possibilidades de perigosos procedimentos efetuados por pessoal não médico.

O equipamento de CPAP apresenta controles aos quais o paciente tem acesso e outros que o paciente jamais poderia manipular, pois referem-se à definição de pressão necessária ao paciente. Ou seja, se estabelecermos que o paciente deva utilizar uma pressão de $9 \mathrm{~cm}$ de $\mathrm{H}_{2} \mathrm{O}$, ela deverá ser mantida até que o médico possa ter a total percepção do efeito terapêutico, efeitos colaterais, envolvimento do paciente no processo de tratamento (perda de peso, mudança de hábitos, etc.), adequação da máscara, dentre outras particularidades do infinito universo multifatorial em que a clínica se encerra.

O médico, após determinadas respostas clínicas, como por exemplo perda de peso, modificações de parâmetros metabólicos, poderá orientar novo ajuste da pressão, tendo procedimentos específicos para isso, e que decidirá no âmbito das visitas clínicas.

A grande preocupação que o tratamento da SAOS com CPAP incita é a possibilidade do paciente manipular deliberadamente a pressão prescrita pelo médico. É exatamente a mesma coisa que acontece quando um paciente faz experiências com determinado medicamento, tomando-o conforme sua própria avaliação. No caso dos medicamentos, podem ocorrer graves efeitos colaterais, ou ainda não propiciar o tratamento que se supunha. No caso do CPAP, o mesmo problema poderá ocorrer, pois se o paciente tiver acesso aos controles de pressão do CPAP, poderá fazer experiências incríveis, como por exemplo aumentar a pressão quando fez uso de bebida alcoólica próximo ao horário de dormir. Tal fato ocorre por exemplo, quando o(a) parceiro(a) de quarto observa que o paciente está roncando. Para interromper o ronco, basta acordá-lo, e ele per se, aumentará a pressão do CPAP para que o ronco desapareça. Vale dizer que nesta condição o CPAP passou a fazer parte do universo de variáveis que mascaram hábitos desfavoráveis à saúde.

O paciente poderá estar com péssimos parâmetros metabólicos, com peso ainda maior do que aquele que atingiu num determinado momento do tratamento (e por vários motivos clínicos, incluindo os psiquiátricos), e deixar de comparecer às consultas médicas, porque tem o domínio sobre os controles do CPAP.

Mesmo que raros e associados a particularidades clínicas (traumas crânio-faciais, pós-operatórios, aumento de peso, etc.), o paciente se expõe a vários riscos (barotrauma, pneumotórax, pneumoencéfalo, pneumomediastino, e os mais comuns, hiperinsuflação e apnéia central). Tais riscos o paciente e tampouco o técnico ou fisioterapêuta da empresa podem podem calcular, havendo grande perigo de que complicações importantes possam ocorrer em alguns pacientes.

Uma vez que esta terapêutica está se tornando mais popular e acessível, é fundamental que os médicos tenham extremo cuidado com o que pode estar se passando com seus pacientes. A prescrição do CPAP e modificações de seus parâmetros é ato médico, e qualquer outro profissional que estiver encarregado de manipular os controles do aparelho, deverá se ater ao que a receita médica prescreve!. Jamais um técnico, vendedor, fisioterapêuta ou mesmo médico poderá desvelar os códigos de manipulação de pressão do equipamento de CPAP ao paciente. Este procedimento além de lesivo diretamente, indiretamente rompe toda relação médico paciente, e principalmente, impede que a complexa abordagem médica exigida por determinados pacientes, seja levada adiante em sua totalidade. O médico trata um paciente e não uma doença, no caso a apnéia. O médico se responsabiliza pelo todo clínico e só ele sabe o que, quando e como modificar parâmetros terapêticos.

Uma sugestão aos colegas, com problemas como os expostos, é que denunciem aos Conselhos Regionais de Medicina as práticas que julgarem incompatíveis com a melhor e mais ética atenção aos pacientes com SAOS. Não é possível que uma companhia revendedora de CPAP (ou qualquer outro positive aimay pressure device), interfira no tratamento de um paciente, oferecendo-lhe a oportunidade de realizar experiências terapêuticas. Em hipótese alguma, mesmo que o paciente more em local distante, ele poderá por si só ter acesso aos controles do equipamento.

Prof. Dr. Gilmar Fernandes do Prado Diretor do Laboratório de Sono Hospital São Paulo - UNIFESP 